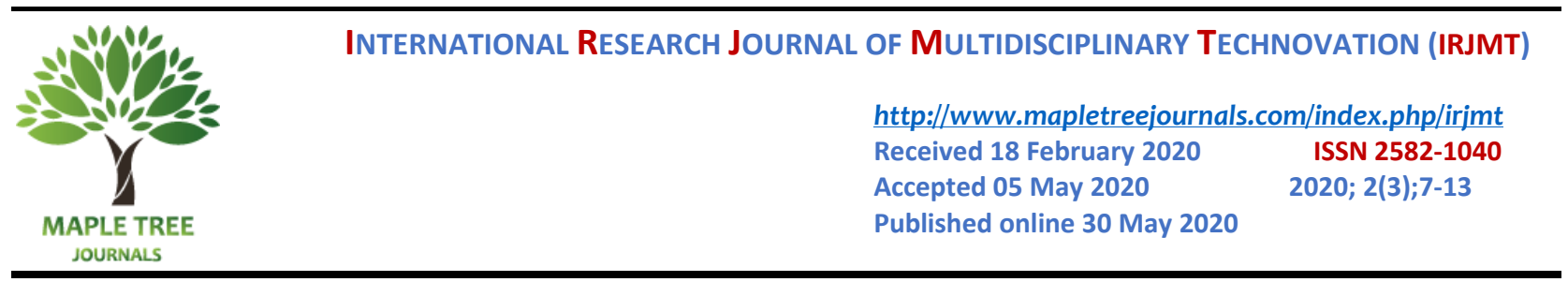

\title{
Smart Metering System with Google Assistant
}

\author{
Ann Maria Jaison 1, *, P. Julian Benadit ${ }^{1}$, Kukatlapalli Pradeep kumar ${ }^{1}$ \\ ${ }^{1}$ Department of Computer Sciences of Engineering, Christ University, Bangalore, India. \\ *Corresponding author E-Mail ID: ann.maria@mtech.christuniversity.in
}

DOI: https://doi.org/10.34256/irjmt2032

\begin{abstract}
This paper presents a unique research problem in the area of automation system by using IoT. The mentioned approach utilizes Google assistant, which is incorporated within Google home which uses voice-controlled inputs and voice feedbacks. This paper discusses a new method to develop a smart energy meter at a distributor level and to make use of this technology to monitor the power consumption of each device individually which can help the user to monitor the electricity usage in real time and thus helps to save electricity and reduce cost on your electricity bill.
\end{abstract}

Keywords: Google Assistant, Node MCU, Metering system, Internet of Things.

\section{Introduction}

IoT is a platform where we can connect home products (things) which are embedded with software, electronics and many sensors interacting with the internet making them fetch and push the data. A smart home makes use of an IoT based application to utilizes internet to control and monitor appliances using a smart automation system [1]. Fig. 1 shows a home automation based smart system. A lot of smart devices like smart T.V., refrigerators, and smartphones are a necessary for people in daily life. Smart home automation systems can help smart devices to communicate with each other [1].

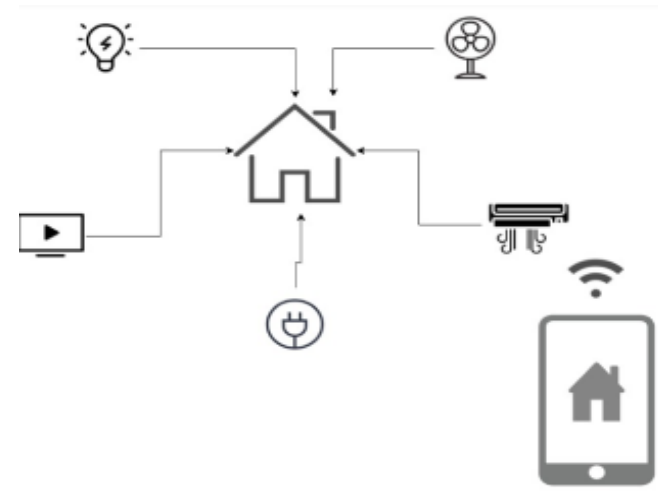

Fig1. A Smart Home Automation System

Electricity is a must in everyday life. We can never imagine a life without electricity. It has also become a major factor in the growth of our country. We depend on electricity for most of our needs. As the demand for electricity is growing each day along with its increasing cost it is necessary to maintain and manage our monthly bill. 
The best solution is to make use of a smart home automation system via Google assistant along with a smart metering system to control the electricity usage. Here, electronic devices like bulb, fan, T.V etc. can be controlled by using Google Assistant. This helps us to pre-calculate how much energy is used by each individual device with the help of a metering system by setting a maximum unit for each device used. If it overcomes the max unit, a notification message will be sent the owner's phone. Using the smart metering system, we can limit the over usage of electricity.

This paper is formulated in the following way. Section 2 briefly explains the related work about IoT and smart home automation system. Section 3 explains the architecture diagram of the proposed problem. Here, it also shows how a smart home automated system works with the help of Google assistant and how it integrates with this smart metering system. Section 4 explains an equation which is used for finding the electricity usage of an LED. Section 5 shows results and Section 6 consists of conclusion and future scope.

\section{Literature Review}

\section{A. About home automation via google assistant}

Home appliances automatically operate by using internet connection without human interference. This concept is known as Smart Home. The smart home automation system provides a comfortable intelligent management system and security that improves the quality of life. By using home automation, we can reduce our electricity bill and save energy. In the year of 2019, Mukherjee presented a low cost, efficient and effective smart home automation system. There are two modules in this system hardware interface module that connects with the internet and software communication module. Here they used an Arduino microcontroller [2]. By using smart plugs, smart cameras, Google home, Google Assistant we can make use of voice commands for controlling electrical appliances at our home. It can be extremely useful for the physical challenged to control electrical devices like fan, bulb etc. [3]. Jabbar developed an IoT@me prototype for monitoring and controlling home appliances. By collecting data from different sensors, it can be accessed by IFTTT (If This Then That) which can update the collected data to adafruitIO's cloud server feeds which operates with Node MCU [4]. Today, voice commands are used for several purposes like controlling lights, playing music etc. [5].

\section{B. Smart Metering System Via Google Assistant}

Sadi Mahmud proposed a smart home automation and metering system. He designed a website to control all home appliances and other electronic devices, he also added a smart online billing system [6]. This paper discussed an energy management system based on IoT. Here data is collected from a smart energy meter using GPRS and displayed it on a website [7]. Another similar work was proposed by Shibu N.B and Rohith. In their research, they designed a smart energy meter with a remote loaded management system. A smart energy meter provides power consumption data. It helps to consumer to manage their energy and its use. The energy data is visualized using a mobile application and can also control home appliances [8]. An Arduino mega microcontroller is used to build a home automation system. Several sensors are used for measuring temperature, humidity and motions at home. A relay board is connected to the automation system to control home appliance through Wi-Fi, An Arduino microcontroller is used for this. It is used for performing calculations and collecting data for any extra energy readings [9].

In the year 2019, Weixian developed a Smart energy theft system based on machine learning and statistical models. Here the system combines various machine learning models for predicting the power consumption. Multi-layer perceptron, Recurrent neural network and gated 
recurrent unit are the machine learning models used for predicting power consumption [10]. Miškuf discussed a smart metering system based on Node MCU which was intergraded with cloud. It contains huge amount of data and information, for storing this information, a cloud platform is used. Now-a-days, a lot of cloud platforms are available but are not based on IoT. The IoT dedicated platforms provide various tools and services for secure communication, device monitoring and its management and visualization of gathering data. Microsoft's power BI tool is used for data visualization and monitoring [9]. By using a single networking protocol, we can store the energy consumption by reading the data collected and pushing it to the cloud so any user can view the data from this energy meter. This data is exchanged to the power dispersion board and its information is collected by the web and sent as a notification through the web to get the per unit usage of the meter [11]. Arora and Taylor explained how the energy estimates can be recorded by each individual device which would help the consumer to understand how much was consumed $[12,4]$.

\section{System Architecture Diagram}

In this project, we are building a smart home automation system using Google assistant which can control home devices like light, switches, fan etc. and also aims to develop a smart metering system to control the usage of electricity. This application includes Google Assistance together with Adafruit's IO server and IFTTT service. The input voice commands are provided to the Google Assistant which works with the IFTTT and Adafruit IO, the commands are then decoded and then sent through the cloud services to the Node MCU micro-controller which controls the relay board that is connected to the devices.

\section{A. Node MCU}

It is an open-source cheap development board unit that lets you to create your own IoT product within a couple of Lua script code. It is an open source programming equipment with improvements that works around a reasonable System-on-a-Chip (SoC) called the ESP8266. It also resembles an Arduino device. There is a Version 2 (V2) accessible from Node-MCU Dev Kit the Node-MCU Development Board v1.0 (V2) is quite different from the v0.9 (V1), which is manufactured as a black PCB.

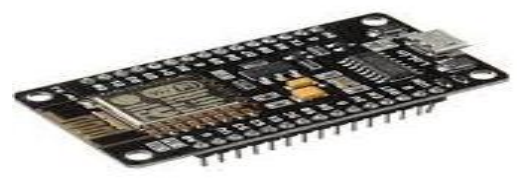

Fig 2. Node MCU

\section{B. Google Assistant}

Google Assistant is a conversational, voice-actuated computerized virtual AI made by Google that can perform activities for a client and provide relevant data and performs voice instructed tasks. To play out its capabilities, Google Assistant depends on a man-made brainpower (AI) innovation, it is designed for regular language interpretation and to understand what the client is stating, and to make proposals or follow ups absed on that language input.

\section{Relay Board}

Relay boards are circuit breaker boards. They can control terminals and are intended to control the voltage supply. Relay boards can be autonomously programmable, ongoing control for every few installed hand-off channel. 


\section{IFTTT}

IFTTT (IF THIS THEN THAT) is a straight forward conditional statement, which makes use of an applet in addition to its online application, its administration runs on iOS and Android.

\section{Working Model}

In this proposed system, we are building a smart metering system. As the part of this project we can control home appliances by using Google Assistant. By using voice commands, it is possible to control home appliances like bulb, A.C, TV etc. Here, we control an LED by using a Google Assistant service along with Adafruit's IO server and IFTTT service. First, we create an Adafruit account. After signing in we have to create a new dashboard with a name and save it. It has an UI to control the lights ON or OFF. Here we use 0 (for OFF) and 1 (for ON) as buttons to control these things remotely. When we make use of a few voice commands like "Ok Google, turn the light ON", IFTTT interprets the command and sends it to the Adafruit IO's dashboard to fire a trigger. For developing a smart metering system, we make use of Node-MCU as the hardware component. Here, we could calculate the power consumption of an LED light with the simple equations which are explained in the section 4.1. By monitoring power consumption individually, we can find which device uses more energy and its use can be limited. To be able to know the power consumption, we could use voice commands like "What is the power consumption?" which voice feedbacks "light 1 has consumed $3 \mathrm{~W}$, light 2 has consumed $3 \mathrm{~W}$, fan 1 has consumed $5 \mathrm{~W}$ " which is displayed on the phone and Display And also warns with a message on the Display, for which we have to set a threshold value which would cause this warning.

\section{Equations}

The electrical power is the ratio of electric energy per time. The unit for this is Watts. Power is calculated by using the below equation

$\mathrm{P}=\mathrm{V} * \mathrm{I}$

Where,

$\mathrm{V}$ - voltage (in Volts)

$\mathrm{I}$ - current (in Amperes)

$\mathrm{P}$ - Power (in Watts)

From (1), LED power can be calculated by multiplying the LED's current by voltage, we have to find the voltage for LED which is in the Table 1.

Table 1. LED's Voltage

\begin{tabular}{|c|c|}
\hline LED & Voltage \\
\hline WHITE & 3.5 \\
\hline RED & 1.8 \\
\hline BLUE & 3.6 \\
\hline GREEN & 2.1 \\
\hline
\end{tabular}

For orange and yellow LED its $2.1 \mathrm{~V}$ only. Once we know the voltage, we will have to determine the current. This can be measured by a multi-meter. For standard LEDs of $5 \mathrm{~mm}$ diameter, the maximum current is $20 \mathrm{~mA} .10 \mathrm{~mA}$ or $15 \mathrm{~mA}$ are the suitable values for many circuits. 
- To convert mA to A

$$
\mathrm{A}=\mathrm{mA} / 1000
$$

For calculating power for LED

$$
\text { LED }=\text { LED voltage } * \text { LED current }
$$

$* 1000$ milli watts $=1 \mathrm{~W}$

\section{Results}

The below Fig. 3 to Fig. 6 shows the use of Google Assistant for the use of smart metering system.

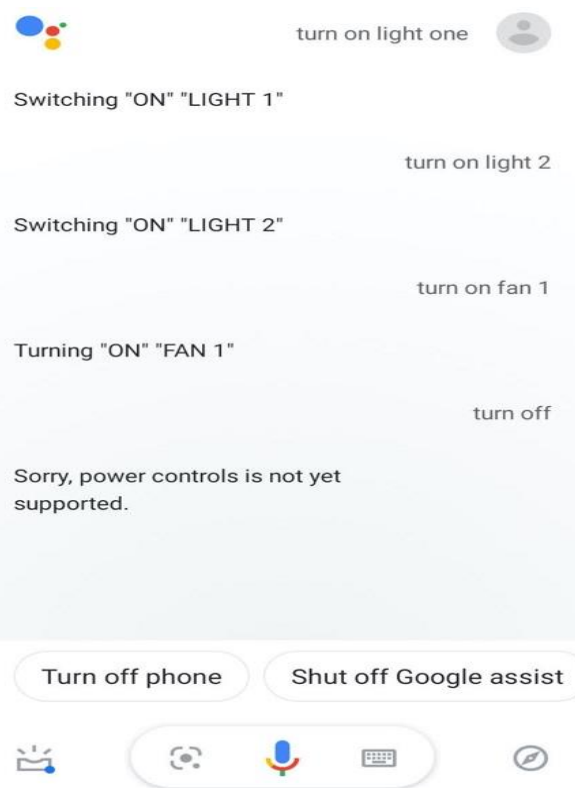

Fig 3. Google Assistant Voice input / output

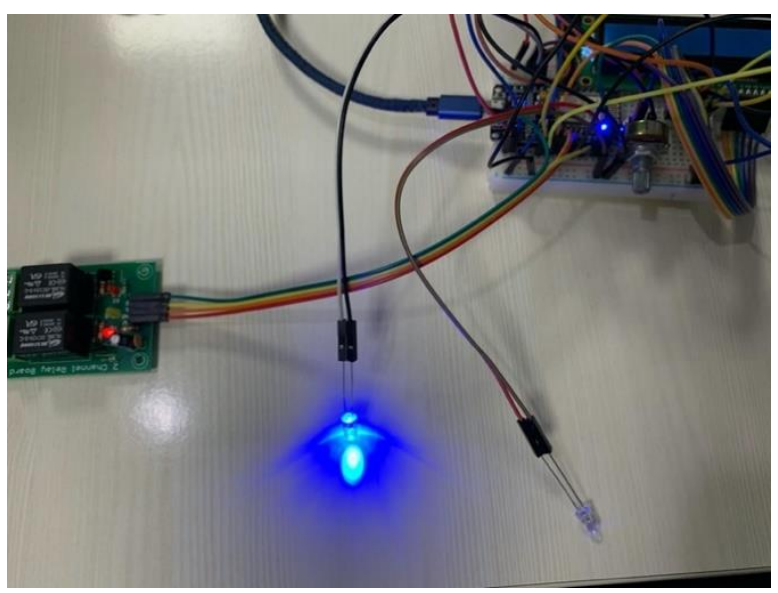

Fig 4. Light Controlled with Voice Input 


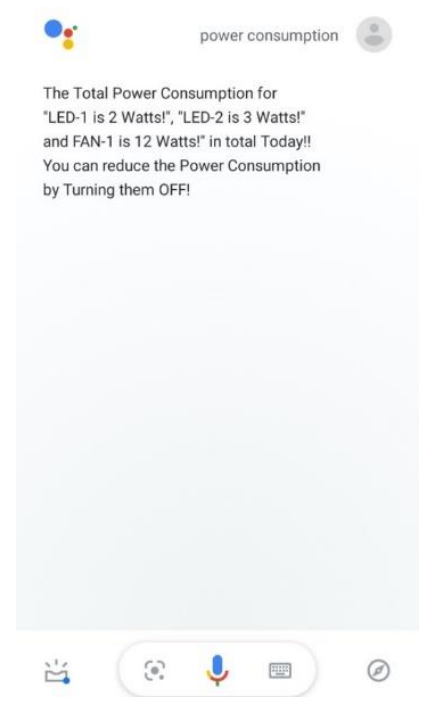

Fig 5. Power consumption Feedback Google Fig 6. Working of the Metering System

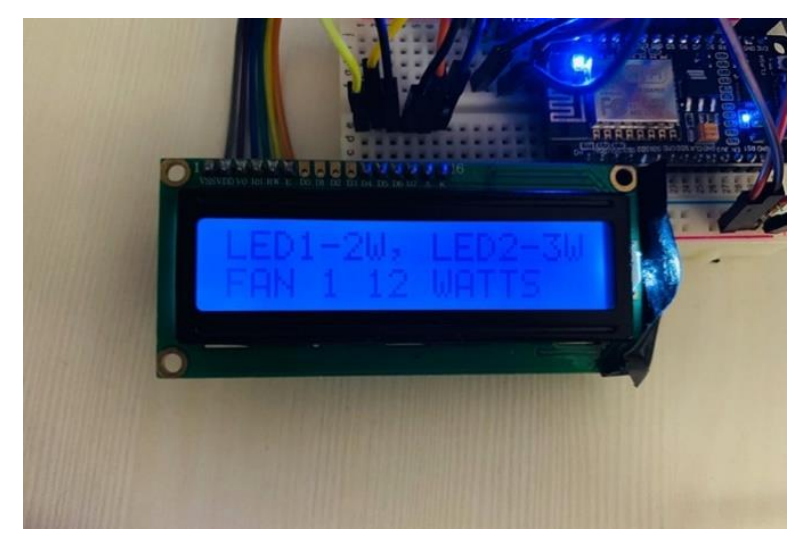

\section{Conclusion and Future Scope}

This paper has presented a smart metering system via Google assistant and controlling devices. It's easier to comparing with website or any mobile applications. Because every phone has integrated with Google assistant/Siri so we don’t want to build any website or applications. Smart metering systems are thus an indispensable part of the evolving technology for a smart home. Its application in various fields and has a lot of benefits. However, its design should meet some pre-laid standards.

In the future database can be integrated to create a dashboard to visualize each month usage and to calculate monthly and yearly bill, so that it becomes easier to save electricity.

\section{References}

[1] W. A. Jabbar, T. K. Kian, R. M. Ramli, S. N. Zubir, N. S. Zamrizaman, M. Balfaqih, S. Alharbi, Design and Fabrication of Smart Home with Internet of Things Enabled Automation System, IEEE Access, 7 (2019) 144059-144074.

[2] D. Mukherjee, S. Kundu, T. Kar, A. Chakraborty, (2019) Controlling Multiple Home Appliances Through Google Assistant and Monitoring Sensor's Data from Server, In 2019 9th Annual Information Technology, Electromechanical Engineering and Microelectronics Conference (IEMECON), IEEE, 179-181.

[3] S. Mischie, L. Matiu-Iovan, G. Gasparesc, (2018) Implementation of Google Assistant on Rasberry $\mathrm{Pi}$, In 2018 International Symposium on Electronics and Telecommunications (ISETC), IEEE, 1-4.

[4] W. A. Jabbar, M. H. Alsibai, N. S. S. Amran, S. K. Mahayadin, (2018) Design and Implementation of IoT-Based Automation System for Smart Home, In 2018 International Symposium on Networks, Computers and Communications, IEEE, 1-6.

[5] L. Burbach, P. Halbach, N. Plettenberg, J. Nakayama, M. Ziefle, A. Calero Valdez, (2019) Hey, Siri', 'Ok, Google', 'Alexa'. Acceptance-Relevant Factors of Virtual Voice-Assistants, 
In 2019 IEEE International Professional Communication Conference (ProComm), IEEE, 101111.

[6] S. Mahmud, S. Ahmed, K. Shikder, (2019) A Smart Home Automation and Metering System Using Internet of Things (IoT), In 2019 International Conference on Robotics, Electrical and Signal Processing Techniques (ICREST), IEEE, 451-454.

[7] J. Zheng, D. W. Gao, L. Lin, (2013) Smart Meters in Smart Grid: An Overview, In 2013 IEEE Green Technologies Conference (GreenTech), IEEE, 57-64.

[8] N. B. S. Shibu, A. Hanumanthiah, S. Sai Rohith, C. H. Yaswanth, P. Hemanth Krishna, J. V. S. Pavan, (2018) Development of IoT Enabled Smart Energy Meter with Remote Load Management, n 2018 IEEE International Conference on Computational Intelligence and Computing Research (ICCIC), IEEE, 1-4.

[9] M. Miskuf, E. Kajati, I. Zolotová, Smart Metering Iot Solution Based on Nodemcu For More Accurate Energy Consumption Analysis, International Journal of Internet of Things and Web Services, 2 (2017) 115-121.

[10] W. Li, T. Logenthiran, V. T. Phan, W. L. Woo, A Novel Smart Energy Theft System (SETS) for Iot-Based Smart Home, IEEE Internet of Things Journal, 6 (2019) 5531-5539.

[11] S. P. Sonar, A. Deshpande, Implementing the Energy Meter Consumption Monitoring System using NodeMCU, International Journal of Management, Technology and Engineering, 8 (2018) 2794-2800.

[12] S. Arora, J. W. Taylor, Forecasting Electricity Smart Meter Data Using Conditional Kernel Density Estimation, Omega, 59 (2016) 47-59.

\section{Acknowledgement}

I thank Dr. K Balachandran, HOD of Computer Science and Engineering, for giving me such a wonderful opportunity. I am extremely thankful to my guides Dr. Julian Benadit P, and Pradeep Kumar, who helped and supported me to complete this paper.

\section{Funding}

This study was not funded by any grant

\section{Conflict of interest}

None of the authors have any conflicts of interest to declare.

\section{About The License}

The text of this article is licensed under a Creative Commons Attribution 4.0 International License

\section{Cite this Article}

Ann Maria Jaison, P. Julian Benadit, Kukatlapalli Pradeep kumar, Smart Metering System with Google Assistant, International Research Journal of Multidisciplinary Technovation, Vol 2, Iss 3 (2020) 7-13.

DOI: https://doi.org/10.34256/irjmt2032 